\title{
Application of UAV Photogrammetry on Ecological Restoration of Abandoned Open-pit mines, Northern Anhui Province, China
}

\author{
Hongbao Dai* and Jiying $\mathrm{Xu}^{* *(* * *) \dagger}$ \\ *School of Environment and Surveying Engineering, Suzhou University, Suzhou, 234000, Anhui, China \\ **School of Resources and Civil Engineering, Suzhou University, Suzhou, 234000, Anhui, China \\ ***National Engineering Research Center of Coal Mine Water Hazard Controlling (Suzhou University), \\ Suzhou, 234000, Anhui, China \\ †Corresponding author: Jiying Xu; jiyingxu1986@163.com
}

Nat. Env. \& Poll. Tech.

Website: www.neptjournal.com

Received: 16-04-2021

Revised: 23-05-2021

Accepted: 07-06-2021

Key Words:

UAV

Abandoned mines

Ecological restoration

Earthwork calculation

Photogrammetry technology

\begin{abstract}
Mine survey is an important part of the ecological restoration design of an abandoned open-pit mine because it gives precise survey data for mine management. Unmanned aerial vehicle (UAV) photogrammetry technology is applied to mine 3D modeling and earthwork calculation to tackle the problems of high cost, low efficiency, and high labor intensity in traditional manual field mine surveys. Using the abandoned quarries in Baitu, Suzhou City, as the study area, 82 ground control points were set up, and massive elevation data of the ground was obtained using a Dajiang spirit 4 RTK UAV for aerial photography and extracted from a 3D model created with Context Capture software, while a digital orthophoto image of the study area was created. The earthwork volume is calculated using the square grid method. UAV photogrammetry has a considerably higher efficiency than typical manual field measurement results, and it meets the precision criteria of mine geological environment assessment. According to the findings, UAV photogrammetry technology has a promising future in mine geological environment monitoring and ecological environment repair.
\end{abstract}

\section{INTRODUCTION}

Mineral resources are the material basis of human economic and social development, and the "food" and main power source of industry, agriculture, national defense, and other social industries (Zhai \& Hu 2021). Large scale and excessive exploitation of mineral resources will bring about environmental problems such as vegetation destruction, soil erosion, ecological environment deterioration, and so on (Hu et al. 2015, Mohammad et al. 2016)(Hu, Fu et al. 2015, Mohammad, Wahsha et al. 2016). Various mines have not returned to their former ecological state after shutting, and there are some issues that need to be addressed, such as land idleness, tailings buildup, ground accretion, and mineral pollution (Sivarajah et al. 2019). The foundation of abandoned mine restoration, land reclamation, and mine green sustainable development is mine ecological environment repair. The mining survey is the key step that can give an accurate measuring basis for the design of ecological restoration during the restoration project (Isiaka et al. 2019).

The traditional manual field mine survey approach, which employs a total station and GPS technology, has drawbacks such as expensive costs, long lead times, and vulnerability to the field environment, among others (Jie et al. 2018). The 3D laser scanning technology has been used in mine geological monitoring because of its advantages of telemetry, speed, and efficiency, but it also has the disadvantages of high labor intensity and inability to acquire reliable information in the blind area (Thurley et al. 2015). The key difficulty in the field of mine survey is how to lower costs while maintaining high quality and efficient access to geometric information and physical properties of mining areas. In recent years, (unmanned aerial vehicle) UAV technology has become widely used in a variety of fields, particularly in engineering geology research, including basic theory research (Xing et al. 2011, Shan et al. 2013), rock discontinuity investigation (Salvini et al. 2020), underground tunnel mapping (Wirachman et al. 2010), slope stability analysis (Wang et al. 2019), and landslide deformation monitoring. However, there are few studies on ecological restoration of abandoned open-pit mines using UAV photogrammetry.

The study's goal was to see if UAV photogrammetry might be used to help with open-pit mine ecological restoration. The Dajiang spirit 4 RTK UAV was employed for aerial photography in this paper, with the abandoned quarries in Baitu town of Suzhou City as the study region. Massive elevation data was retrieved from a 3D model created with the Context Capture software. The earthwork 
volume is calculated using the square grid method, and the measurement accuracy is compared to traditional manual field measurement findings. The findings will be used to establish sustainable development plans, as well as to better understand the management and development of abandoned mining resources.

\section{MATERIALS AND METHODS}

\section{Study Area}

The abandoned quarries are located $55 \mathrm{~km}$ north of Suzhou city in Anhui province, China. Its geographical coordinates are $117^{\circ} 2^{\prime} 1^{\prime \prime}-117^{\circ} 7^{\prime} 22^{\prime \prime}$ north and $34^{\circ} 9^{\prime} 26^{\prime \prime}-34^{\circ} 4^{\prime} 32^{\prime \prime}$ east, as shown in Fig. 1. The climate of the study area belongs to the warm temperate zone and semi-humid monsoon section, characterized by a mild climate and four distinct seasons, with an average annual temperature of $14.5^{\circ} \mathrm{C}$ and an average annual rainfall of around $774 \mathrm{~mm}$. Geologically, the quarries area is located between Su Bei Fault and the Feng Pei fault.

The abandoned quarries are limestone mines for building stone, which consist of four mines and cover a damaged area of $322450.8 \mathrm{~m}^{2}$ and an undamaged area of the original mountain $68226.5 \mathrm{~m}^{2}$ respectively (Fig. 1). In the study region, there are several dangerous rocks, and the rock at the top of the cliff face is relatively shattered. There is a risk of geological disasters such as collapse and landslides as a result of local slope mining along the rock layers.

\section{Principle of Photogrammetry}

UAV photogrammetry uses theories and algorithms such as computer technology, digital picture feature extraction, and image matching to create a three-dimensional model and extract relevant geometric and physical information, all based on the basic principle of photogrammetry (Lin et al. 2018, Wang et al. 2020). The image-object relationship model is constructed based on the collinear relationship of the image point, photogrammetry center, and object point (Qiang \& Tian 2019).

$$
\begin{aligned}
& x-x_{0}=-f \frac{a_{1}\left(X-X_{S}\right)+b_{1}\left(Y-Y_{S}\right)+c_{1}\left(Z-Z_{S}\right)}{a_{3}\left(X-X_{S}\right)+b_{3}\left(Y-Y_{S}\right)+c_{3}\left(Z-Z_{S}\right)} \\
& y-y_{0}=-f \frac{a_{2}\left(X-X_{S}\right)+b_{2}\left(Y-Y_{S}\right)+c_{2}\left(Z-Z_{S}\right)}{a_{3}\left(X-X_{S}\right)+b_{3}\left(Y-Y_{S}\right)+c_{3}\left(Z-Z_{S}\right)}
\end{aligned}
$$

The photographing scale is determined by the focal length $f$ and the height $h$ of the camera (Meng et al. 2020). According to the photographing scale and the pixel size $a$ of the camera, the ground resolution $\mathrm{G}$ can be determined by the formula (2).

$$
\frac{1}{m}=\frac{F}{H}=\frac{a}{G}
$$

In the formula (2): $1 / \mathrm{m}$ represents photographing scale.

\section{Principle of Square Grid Method}

The square grid method is common and effective in earthwork calculation (Zhang et al. 2015, Guo et al. 2016). The calculation steps are as follows: (1) the study area is divided into several squares. (2) For each grid, the product of the grid area and difference value (between design elevation and measured elevation) is regarded as the engineering quantity of a single grid. (3) The calculation results of each grid are accumulated to obtain the total quantities of the study area.

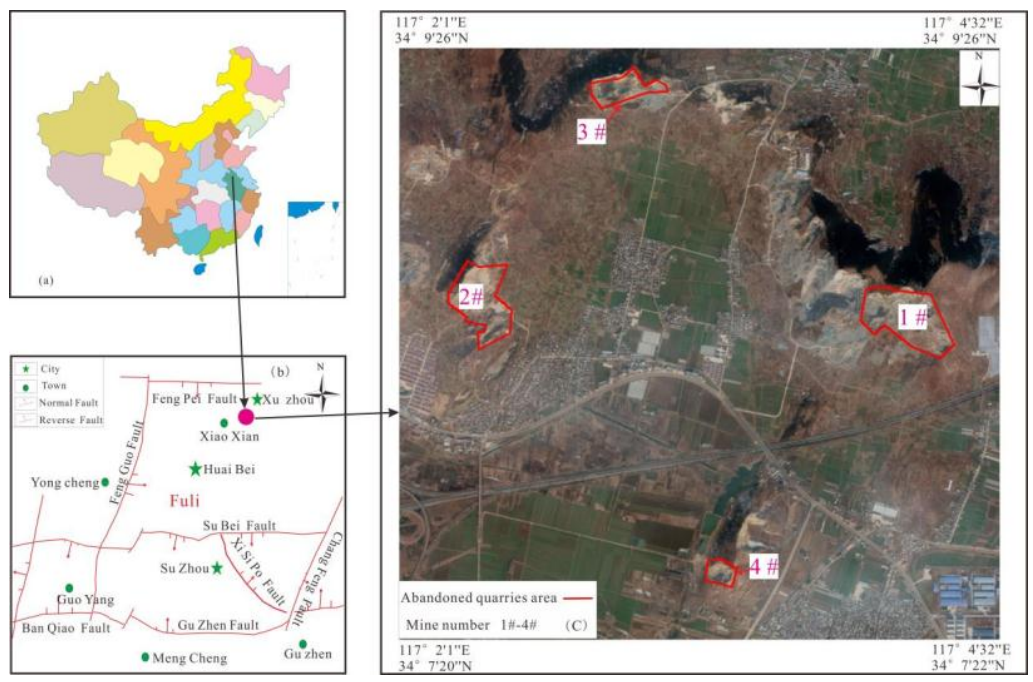

Fig. 1: Geographical location map of the study area. 
The calculation formula is shown in (3) (4).

$$
\begin{gathered}
H_{i j}=\frac{1}{k} \sum_{j=1}^{k}\left(H_{j}-H_{D}\right) \\
V=\sum_{i=1}^{n} H_{i j} a b
\end{gathered}
$$

In the formula (3): $\mathrm{H}_{\mathrm{ij}}$ is the elevation of $\mathrm{i}$ row and $\mathrm{j}$ column grid; $\mathrm{K}$ represents the number of points in the grid; $\mathrm{H}_{\mathrm{j}}$ is the actual elevation of points in the grid; $\mathrm{H}_{\mathrm{D}}$ is the design elevation. In the formula (4): V represents the total amount of work; $n$ is the number of squares in the survey area; $a$ and $\mathrm{b}$ are the side length of the grid respectively.

Backfill in earthwork should be taken during ecological restoration if the design elevation is higher than the observed elevation. On the other hand, if the design elevation is lower than the observed elevation, excavation measures should be taken. Furthermore, a significant number of elevation data are generated in a single grid due to the dense matching program of UAV photogrammetry, and the measured height can use the average value of all elevation data in the grid to ensure accuracy.

\section{Three-Dimensional (3D) Modeling}

Control surveying and UAV route planning were used in the project to gather images of abandoned quarries (He et al. 2020). Using context capture software, a 3D model was created, and the geometric information for the earthwork computation was extracted from the model.

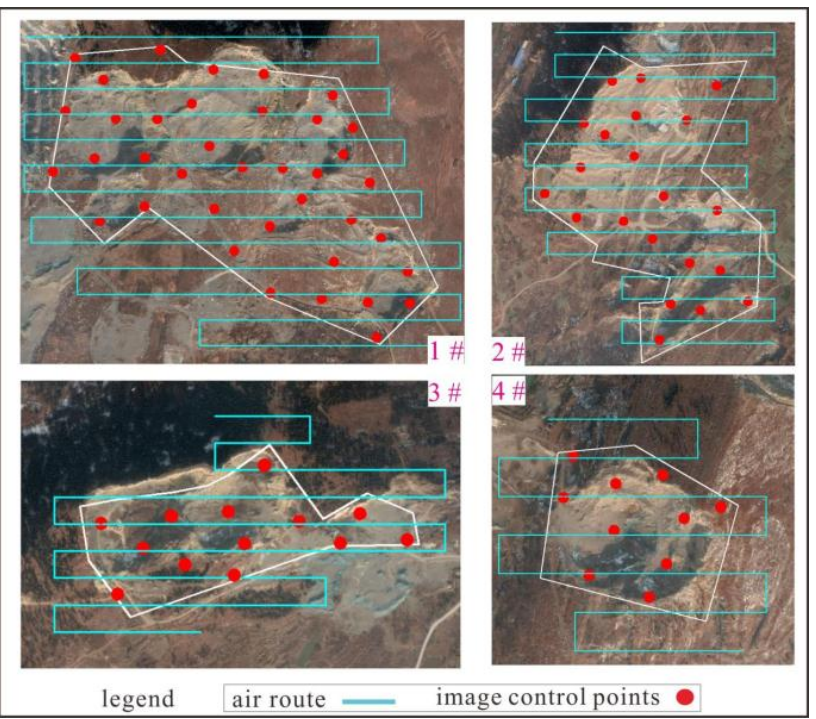

Fig. 2: Layout of image control points and routes in the study area.

\section{Control Surveying}

The photo control points are primarily used for photogrammetric picture recognition, which is often based on the principle of "more around, less in the middle," and is in accordance with the coordinate system developed afterwards (Sun et al. 2018). To make the control network more stable and match the accuracy requirements, 82 image control points (Fig. 2) are set up in the study region due to the substantial topography fluctuation of the open-pit quarry.

\section{UAV Image Acquisition}

There are several high and steep slopes in the research region, with a maximum slope of $80^{\circ}$ and a difference between the platform surface and the top of the hill in the treatment area ranging from 90 to $140 \mathrm{~m}$, due to the influence of mining technologies and natural conditions. As a result, the study area's layers and blocks follow the design path (Xu et al. 2016). The center of each block area is chosen as the flight site to assure the quality of the images. The relative elevation of the study area is higher during the field survey, the wind speed is strong and changes often, and the field aerial survey difficulty coefficient is higher than that of residential aerial survey.

The UAV of Dajiang spirit 4 RTK was used to obtain the image. To meet the accuracy requirements of earthwork

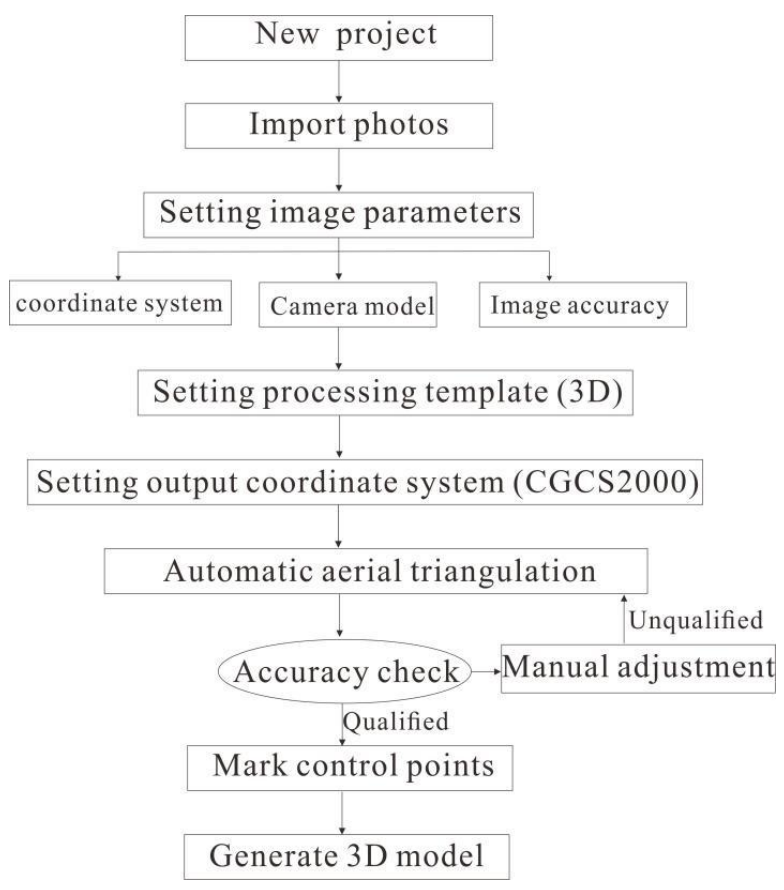

Fig. 3: Flow chart of 3D modeling. 
calculation, the mapping scale of 1:1000 and the photography scale of 1:5000 are selected. The designed altitude is set at $90 \mathrm{~m}$, and the overlap of heading and side direction is $80 \%$. A total of 12 routes (Fig. 2) are arranged, flying in three voyages, and the horizontal flight speed is $6 \mathrm{~m} . \mathrm{s}^{-1}$. A total of 805 images were obtained from the front, back, left and right orthophoto 5 cameras, the image size is 5472 pixels $\times$ 3678 pixels, and the average ground resolution of tilt image is $2.08 \mathrm{~cm}$.

\section{D Modeling}

According to the results of the control survey and the images obtained by UAV, the 3D model of the abandoned outcrop mine is established by using context capture software and the process shown in Fig. 3 (Jing et al. 2015). The model post-processing is carried out by using the software of EPT and EPS (encapsulated postscript). The 3D modelings of abandoned mines are shown in Fig.4.

\section{Model Accuracy Evaluation}

Mean square error is often used to evaluate the accuracy of mapping, including $\mathrm{M}_{\mathrm{S}}$ (plane) and $\mathrm{M}_{\mathrm{H}}$ (elevation) (Puliti et al. 2018). The calculation formula is as follows (5), (6), and (7).

$$
\begin{gathered}
M_{S}=\sqrt{\frac{\sum(\Delta S)^{2}}{n}} \\
M_{H}=\sqrt{\frac{\sum(\Delta H)^{2}}{n}} \\
\Delta S=\sqrt{(\Delta X)^{2}+(\Delta Y)^{2}}
\end{gathered}
$$

In the above formulas, the $\Delta \mathrm{s}$ represents the plane distance error, $\Delta \mathrm{x}, \Delta \mathrm{y}$, and $\Delta \mathrm{h}$ represent the absolute error of three-dimensional coordinates respectively, and $\mathrm{n}$ is the number of measuring points. Based on the manual measurement data (measured by total station) and 3D model measurement data (extracted from UAV), $\mathrm{M}_{\mathrm{S}}$ and $\mathrm{M}_{\mathrm{H}}$ are calculated.

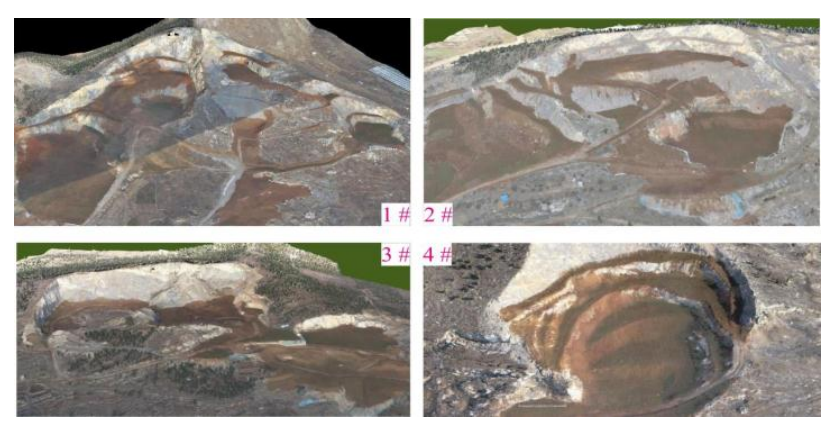

Fig. 4: 3D model of the abandoned quarries.

\section{RESULTS AND DISCUSSION}

First, 50 checking points were evenly selected in the survey area, and the total station was used to obtain the three-dimensional coordinates (X, Y, H); second, the total station measurement results are subtracted from the corresponding 3D model measurement data, and the absolute errors of the $\Delta \mathrm{x}, \Delta \mathrm{y}, \Delta \mathrm{h}$, and $\Delta \mathrm{s}$ are calculated; finally, $\mathrm{M}_{\mathrm{S}}$ and $\mathrm{M}_{\mathrm{H}}$ are used to calculated by the formulas (5), (6) and (7). The accuracy evaluation results of the 3D model in the study area are shown in Table 1.

According to "Specification for aerial photogrammetry of $1: 5001: 10001: 2000$ topographic map" (China National Standardization Committee 2008), $\mathrm{M}_{\mathrm{S}}$ and $\mathrm{M}_{\mathrm{H}}$ of $1: 1000$ topographic map in mountainous and hilly areas should be less than $0.4 \mathrm{~m}$ and $0.35 \mathrm{~m}$ respectively. The calculated results of $\mathrm{M}_{\mathrm{S}}$ and $\mathrm{M}_{\mathrm{H}}$ for the study area are $0.083 \mathrm{~m}$ and $0.069 \mathrm{~m}$ respectively, indicating $3 \mathrm{D}$ modeling meets the accuracy requirements, which can be used for earthwork calculation.

\section{Earthwork Calculation of Abandoned Mines}

Based on the manual measurement data (total station) and 3D model measurement data (extracted from UAV), the volume of earthwork was calculated by the square grid method (Liu et al. 2020). To create the original topographic map and the construction topographic map, the original elevation points and construction elevation points obtained by two types of survey methods are first loaded into Cass 9.1 software. Second, the boundary between filling and excavation is delineated by superimposing and comparing the elevation data of the two maps, and the region is divided into blocks and serially numbered, generating a block map. Finally, the original map and construction map for a single block is superimposed on the block map, and the block's volume $\mathrm{V}_{1}$ and $\mathrm{V}_{2}$ are calculated using 0 elevations as the datum plane and 5 meters as the grid length. The value of $\mathrm{V}_{1}$ minus $\mathrm{V}_{2}$ is the block's excavation or filling volume. Finally, the regional blocks are added together to determine the mine's earthwork volume. Table 2, Fig. 5, and Fig. 6 present the results of four abandoned quarries' calculations.

Hence, the excavation difference between the two methods is $4577.36 \mathrm{~m}^{3}$, and the difference rate is between $0.019-0.035$, with an average of 0.023 . Meanwhile, the filling difference between the two methods is $1669.41 \mathrm{~m}^{3}$, and the difference rate is between 0.018-0.014, with an average of 0.020 . The engineering earthwork calculation is a complex problem involving multiple influencing factors, which cannot be accurately calculated in advance, and the current specifications do not specify the error of earthwork measurement. Generally, the error of earthwork measurement from relatively flat to uneven is controlled within $5 \%(\mathrm{Li}$ 
Table 1: The calculation results of accuracy evaluation.

\begin{tabular}{|c|c|c|c|c|c|c|c|c|c|}
\hline point & $\Delta \mathrm{X}(\mathrm{m})$ & $\Delta \mathrm{Y}(\mathrm{m})$ & $\Delta \mathrm{H}(\mathrm{m})$ & $\Delta \mathrm{S}(\mathrm{m})$ & point & $\Delta \mathrm{X}(\mathrm{m})$ & $\Delta \mathrm{Y}(\mathrm{m})$ & $\Delta \mathrm{H}(\mathrm{m})$ & $\Delta \mathrm{S}(\mathrm{m})$ \\
\hline 1 & -0.018 & 0.043 & 0.056 & 0.047 & 26 & 0.061 & 0.029 & 0.042 & 0.068 \\
\hline 2 & 0.053 & 0.021 & 0.034 & 0.057 & 27 & 0.025 & -0.082 & -0.069 & 0.086 \\
\hline 3 & 0.017 & -0.090 & -0.077 & 0.092 & 28 & -0.013 & 0.048 & 0.061 & 0.050 \\
\hline 4 & -0.021 & 0.040 & 0.053 & 0.045 & 29 & 0.057 & 0.077 & 0.090 & 0.096 \\
\hline 5 & 0.049 & 0.089 & 0.102 & 0.102 & 30 & 0.026 & 0.058 & 0.071 & 0.064 \\
\hline 6 & 0.018 & 0.070 & 0.083 & 0.072 & 31 & -0.085 & 0.022 & 0.135 & 0.088 \\
\hline 7 & -0.093 & 0.134 & 0.087 & 0.163 & 32 & 0.045 & -0.016 & -0.003 & 0.048 \\
\hline 8 & 0.037 & -0.004 & 0.009 & 0.037 & 33 & 0.074 & 0.054 & 0.067 & 0.092 \\
\hline 9 & 0.086 & 0.066 & 0.079 & 0.108 & 34 & 0.055 & 0.023 & 0.036 & 0.060 \\
\hline 10 & 0.067 & 0.035 & 0.048 & 0.076 & 35 & 0.019 & -0.088 & -0.075 & 0.090 \\
\hline 11 & 0.031 & -0.076 & -0.063 & 0.082 & 36 & -0.019 & 0.042 & 0.055 & 0.046 \\
\hline 12 & -0.007 & 0.054 & 0.067 & 0.054 & 37 & 0.051 & 0.091 & 0.104 & 0.104 \\
\hline 13 & 0.063 & 0.069 & 0.082 & 0.093 & 38 & 0.020 & 0.072 & 0.085 & 0.075 \\
\hline 14 & 0.032 & 0.050 & 0.063 & 0.059 & 39 & -0.091 & 0.136 & 0.149 & 0.164 \\
\hline 15 & -0.079 & 0.014 & 0.027 & 0.080 & 40 & 0.039 & -0.002 & 0.011 & 0.039 \\
\hline 16 & 0.051 & -0.024 & -0.011 & 0.056 & 41 & 0.088 & 0.068 & 0.081 & 0.111 \\
\hline 17 & 0.066 & 0.046 & 0.059 & 0.080 & 42 & 0.069 & 0.037 & 0.050 & 0.078 \\
\hline 18 & 0.047 & 0.015 & 0.028 & 0.049 & 43 & 0.033 & -0.074 & -0.061 & 0.081 \\
\hline 19 & -0.089 & -0.096 & -0.083 & 0.131 & 44 & -0.005 & 0.056 & 0.069 & 0.056 \\
\hline 20 & -0.027 & 0.034 & 0.047 & 0.043 & 45 & 0.065 & 0.071 & 0.084 & 0.096 \\
\hline 21 & 0.043 & 0.083 & 0.096 & 0.093 & 46 & 0.034 & 0.052 & 0.065 & 0.062 \\
\hline 22 & 0.012 & 0.064 & 0.077 & 0.065 & 47 & -0.077 & 0.054 & 0.067 & 0.094 \\
\hline 23 & -0.099 & 0.039 & 0.031 & 0.106 & 48 & 0.053 & 0.023 & 0.036 & 0.058 \\
\hline 24 & 0.031 & -0.010 & 0.003 & 0.033 & 49 & 0.068 & -0.058 & -0.075 & 0.089 \\
\hline 25 & 0.080 & 0.060 & 0.073 & 0.100 & 50 & 0.049 & 0.042 & 0.055 & 0.065 \\
\hline
\end{tabular}

\& Yang 2020, Contreras \& Chung 2012). As a result, the process of determining the earthwork volume of an open pit mine using a UAV aerial survey may fully meet engineering precision criteria.

The workload of manual measurement and UAV is shown in Table 3. Table 3 shows that UAV photogrammetry requires two surveyors and two days for outdoor work, and two surveyors and 2.5 days for indoor work. Manual measurement, on the other hand, necessitates 4 surveyors and 4.75 days for fieldwork, and 1 surveyor and 2.5 days for indoor work. The conclusion can be made that UAV photogrammetry has a substantially higher work efficiency than traditional manual measuring.

\section{CONCLUSION}

(1) Using context capture software, a 3D model of an abandoned mine was created based on the ground control survey and images obtained by the Dajiang spirit 4 RTK UAV. The horizontal and elevation mean square errors are $0.083 \mathrm{~m}$ and $0.069 \mathrm{~m}$, respectively, which meet the accuracy standards.

Table 2: Comparison of earthwork calculation results between manual measurement and UAV.

\begin{tabular}{|clllllll}
\hline No. & $\begin{array}{l}\text { Area } \\
{\left[\mathrm{m}^{2}\right]}\end{array}$ & UAV $\left[\mathrm{m}^{3}\right]$ & $\begin{array}{l}\text { Manual measurement } \\
{\left[\mathrm{m}^{3}\right]}\end{array}$ & Difference rate & UAV $\left[\mathrm{m}^{3}\right]$ & $\begin{array}{l}\text { Manckfill } \\
{\left[\mathrm{m}^{3}\right]}\end{array}$ \\
\hline $1 \#$ & 166821.1 & 195680.31 & 192840.65 & 0.015 & 36182.96 & 36845.52 & 0.018 \\
$2 \#$ & 137486.9 & 58959.95 & 56974.14 & 0.035 & 29147.04 & 29642.73 & 0.017 \\
$3 \#$ & 59779.6 & 59080.51 & 60222.98 & 0.019 & 12520.85 & 12342.92 & 0.014 \\
$4 \#$ & 26589.7 & 42243.72 & 41349.36 & 0.022 & 22226.26 & 22915.35 & 0.030 \\
\hline
\end{tabular}




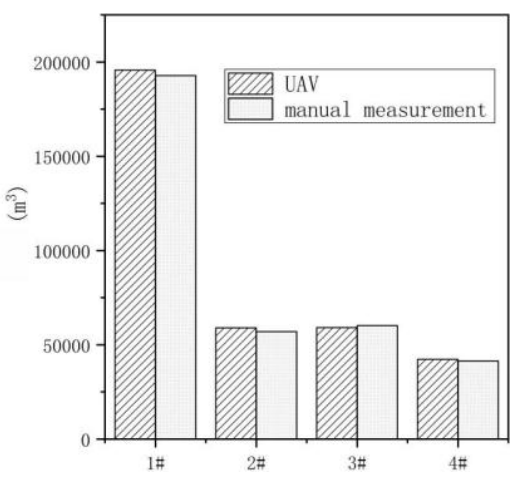

Fig. 5: Comparison chart of earthwork calculation results between manual measurement and UAV.

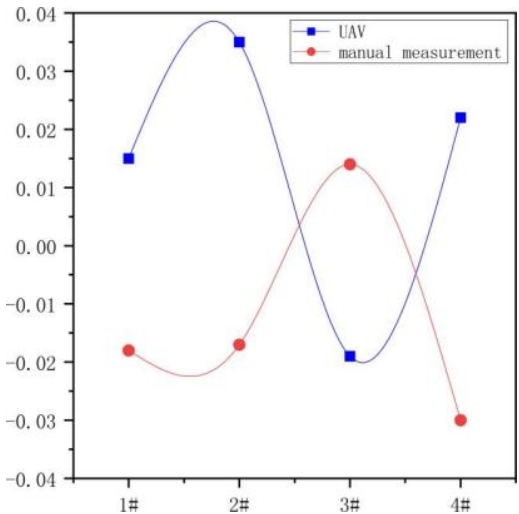

Fig. 6: Difference rate of earthwork calculation results.

Table 3: Workload table of manual measurement and UAV.

\begin{tabular}{|c|c|c|c|c|c|c|c|c|}
\hline \multirow[t]{3}{*}{ No. } & \multicolumn{4}{|c|}{ UAV } & \multicolumn{4}{|c|}{ Manual measurement } \\
\hline & \multicolumn{2}{|c|}{ Field survey } & \multicolumn{2}{|c|}{ indoor work } & \multicolumn{2}{|c|}{ Field survey } & \multicolumn{2}{|r|}{ Indoor work } \\
\hline & Surveyors & Days & & Days & Surveyors & Days & & Days \\
\hline 1 & 2 & 1 & 1 & 1 & 4 & 2 & 2 & 1 \\
\hline 2 & 2 & 0.5 & 1 & 0.5 & 4 & 1 & 2 & 0.5 \\
\hline 3 & 2 & 0.5 & 1 & 0.5 & 4 & 1 & 2 & 0.5 \\
\hline 4 & 2 & 0.5 & 1 & 0.5 & 4 & 0.75 & 2 & 0.5 \\
\hline Total & 2 & 2.5 & 1 & 2.5 & 4 & 4.75 & 2 & 2.5 \\
\hline
\end{tabular}

(2) The earthwork volume was calculated using the square grid method, which was based on data from UAV photogrammetry and a classical total station survey. The average difference rate is 0.022 , which satisfies the earthwork measuring standards. In comparison to traditional field surveys, UAV photogrammetry provides the advantages of a shorter field time and automatic data processing, which considerably enhances labor productivity and is unaffected by external topographical impediments, particularly in large-area surveys.

The 3D mine model has a good overall situation, and it is also an image model that can measure and extract information, which provides significant basic data for mine ecological restoration design, and it has a promising future use in mine ecological restoration.

\section{ACKNOWLEDGEMENT}

This research was funded by the Key natural science research projects of Suzhou University (2020yzd03, 2020yzd07, 2019yzd01), National Natural Science Foundation of China (41773100), and Funding projects for research activities of academic and technological leaders of Anhui Province (2020D239).

\section{REFERENCES}

China National Standardization Committee. 2008. Specification for aerial photogrammetry of $1: 5001: 10001: 2000$ topographic map, 3. Southwest Jiaotong University, GIS Engineering Center, Chengdu, China.

Contreras, A. and Chung, X. 2012. Improving accuracy in earthwork volume estimation for proposed forest roads using a high-resolution digital elevation model. Croatian J. Forest Eng., 33(1): 456-463.

Guo, J., Mingxing, Y.I. and Xue, M.C.C. 2016. Engineering application study of earthwork calculation with square grid method by southern CASS. Min. Eng., 54: 616-636.

He, X., Yang, X., Luo, Z. and Guan, T. 2020. Application of unmanned aerial vehicle (UAV) thermal infrared remote sensing to identify coal fires in the Huojitu coal mine in Shenmu City, China. Sci. Rep., 10(1): 56-71.

Hu, Z.Q., Fu, Y.H., Xiao W. and Wei, T.T. 2015. Ecological restoration plan for an abandoned underground coal mine site in Eastern China. Int.J. Min. Reclam. Environ., 29(4): 316-330.

Isiaka, A.I., Durrheim, R.J. and Manzi, M.S.D. 2019. High-resolution seismic reflection investigation of subsidence and sinkholes at an abandoned coal mine site in South Africa. Pure Appl. Geophys., 176(4): 1531-1548.

Jie, X., Chen, J., Sofia, G., Yi, T. and Tarolli, P.J.E.E.S. 2018. Open-pit mine geomorphic changes analysis using multi-temporal UAV survey. Springer Berlin Heidelberg, 77(6): 1-18.

Jing, Q.Q., Zhi, X.D., Wang, J., Wang, X.H., Amp, A.G. and Center, R.S. 2015. Remote sensing survey of iron mine exploitation using UAV technology in Yuanjiang, Shanxi. Miner. Explor., 2: 79.

Li, W.J. and Yang, J. 2020. The application of UAV Photogrammetry in the Calculation of the amount of Earth and Stone excavation. Beij. Survey. Map., 34(10): 106-109. 
Lin, Z., Xie, F. and Guozhong, S.U. 2018. Accuracy analysis of low altitude photogrammetry with a wide-angle camera. J.Survey. Map., 11(1): 30-38.

Liu, X.Y., Li, Y.P. and Wu, J.C. 2020. Earthwork measurement based on UAV tilt Photogrammetry. Survey. Map. Technol. Equip., 22(01): 53-56.

Meng, Q., Li, W., Raspini, F., Xu, Q. and Casagli, N.J.L. 2020. Time-series analysis of the evolution of large-scale loess landslides using InSAR and UAV photogrammetry techniques: a case study in Hongheyan, Gansu Province, Northwest China. Landslides, 2: 54.

Mohammad, W., Mandana, N. and Claudio, B.J.J.O. 2016. Land contamination by toxic elements in abandoned mine areas in Italy. Soils Sediments, 16(4): 1300-1305.

Puliti, T., Astrup, M. and Forests, R.J. 2018. Tree-stump detection, segmentation, classification, and measurement using unmanned aerial vehicle (UAV) Imagery. Forests, 9(3): 102.

Qiang, L.I. and Tian, L.I. 2019. Application of UAV photogrammetry in reserves calculation in the coal yard. Beij. Survey. Map., 5: 11-29.

Salvini, R., Vanneschi, C., Coggan, J.S. and Mastrorocco, G. 2020. Evaluation of the use of UAV photogrammetry for rock discontinuity roughness characterization. Rock Mech. Rock Eng., 53(8): 3699-3720.

Shan, B.J., LuoXu, Y.Y. and Liang, L.X. 2013. Application of UAV in open-pit mine disaster monitoring. Opencast Min. Technol., 8: 63-78.

Sivarajah, B.J.B., Korosi, J.M., Blais, R.M. and Smol, J.P. 2019. Multiple environmental variables influence diatom assemblages across an arsenic gradient in 33 subarctic lakes near abandoned gold mines. Hydrobiologia, 841(1): 133-151.
Sun, K., Zhao, K. and Liu, Y. 2018. Research on the influence of photo-control-points layout on aero-triangulation accuracy by UAV aerial in zonal terrain. Western Devel., 16(9): 111-123.

Thurley, M.J., Onederra, I., Catalan, M. and Metallurgy, S. A. 2015. Measuring blast fragmentation at Esperanza mine using high-resolution 3D laser scanning. Min. Technol., 11: 54-63.

Wang, F.Y., Zhao, M.Y., Wang, M.C., Zhang, J.Q. and Zhou, K. 2020. Application of UAV Photogrammetry in mine geological environment survey. J. Jilin Univ., 50(03): 194-202.

Wang, S., Ahmed, Z., Hashmi, M.Z. and Wang, P.G.F. 2019. Cliff faces rock slope stability analysis based on unmanned aerial vehicle (UAV) photogrammetry. Geo-Energy Geo-Resour., 46: 537-553.

Wirachman, W., Wahyu, K., Nasir, R.M. and Aman, M.R. 2010. Aerodynamics prediction of Blended Wing Body (BWB) Unmanned Aerial Vehicle (UAV) using wind tunnel experimental approach. Development and Commercialization, Universiti Teknologi MARA, Malaysia.

Xing, X.J., Yan, J.G. and Yuan, D.L. 2011. Augmented-stability controller design and its simulation for a UAV based on LQR theory. Flight Dyn., 11: 98-121.

Xu, Z.H. , Wu, L.X., Chen, S.J. and Wang, Z. 2016. Method of engineering volume monitoring and calculation for open-pit mine from UAV images. J. Northeastern Univ. Nat. Sci., 15: 413-429.

Zhai, M.G. and Hu, B. 2021. Thinking to state security, international competition, and national strategy of mineral resources. J.Earth Sci. Environ., 43(1): 1-11.

Zhang, S.Y., Wang, R.H. and Dong-Mei, L.I. 2015. Earthwork calculation by CASS2008 square grid method. Jilin Geol., 5(9): 35-47. 